\title{
A Dutch report on the ethics of neonatal care a commentary
}

\author{
R P A Rivers St Mary's Hospital Medical School, London
}

\begin{abstract}
The moral arguments and the decision-making processes arising from them in the context of the dilemmas that arise in considering the appropriateness and implementation of withholding or withdrawing treatment in certain neonates form the basis of this commentary.

It is concluded that the differing opinions on management of these babies by individual paediatricians results from their differing moral outlooks rather than from any incoherence in the moral arguments set out in the Dutch report.
\end{abstract}

The principles on which the decision to continue or discontinue life-prolonging medical treatment for babies and the consequences of the decision, once reached, are set out in the Dutch report Doen of Laten? (To Do or Not To Do?) summarized by Versluys and de Leeuw (1). They have been further discussed by Sauer (2). In arriving at a decision, the questions listed under 'must be asked' derive from the moral standpoint that under certain circumstances, neonates lose the right to have their lives prolonged through surgical, medical or possibly 'routine' interventions. The rights themselves are often seen to derive from the fact that neonates either have, or possess a potential to develop, the attributes of personhood including self-awareness, the capacity to reason and experience emotional interactions with others, and to formulate objectives based on experience which they may then achieve by initiating appropriate actions. This development of an individual human identity or personality which can be expressed has been offered as the justification for providing lifesaving care for newborns, including very prematurely born babies. Such a moral standpoint, whereby some infants may be seen to be 'so disabled that they can never become persons with the rights that accompany this status' (3) is, however, quite unacceptable to many paediatricians and child-carers.

\section{Key words}

Newborn; life-prolonging treatment; euthanasia; ethics.
None the less, the three alternative types of care described in this report, viz continue maximum intensive care and extend if necessary, maintain status quo, stop the most intensive form of treatment (with a view to allowing the infant to die); would find support among most practising neonatologists and would account for some half or more deaths occurring in neonatal intensive care units in the UK today.

Difficulties arise (a) when it is agreed that there is a loss of rights to have life prolonged and, following withdrawal of ventilator care, life continues; (b) when there is every indication that with continuing nutrition and baby care, the child will live and (c) in the consideration of whether there is a moral distinction to be made between discontinuing intensive (for example, ventilator) care and discontinuing 'normal' care, such as feeding via a tube into the stomach - a form of support required by all prematurely born infants before they develop the capacity to co-ordinate sucking and swallowing and by very brain-damaged infants whose neurodevelopmental maturation has been interrupted.

So far as (c) is concerned, a cogent moral argument has been presented for considering the two levels of care equally in terms of withdrawal when considering the discontinuation of lifeprolonging therapies (3). If good moral practice embodies the notion that the clinician should always act in a child's best interests, then it may be seen that the continuation of any level of care, in the face of a predicted very severe outcome for the baby, could be regarded as irresponsible behaviour; care, in this context, would include even basic requirements such as food and hydration though not the provision of warmth and normal hygiene. It has also been argued that even where parents might wish treatment to continue, there could be circumstances under which it would be morally encumbent on the clinician to refuse to initiate further treatment if, by adopting that stance, he or she would be acting in the best interests of the child.

However, as indicated in the Dutch report, and as expressed by many practising neonatologists, the translation of this moral argument into clinical neonatal practice would not receive wide support, 
and in particular most neonatologists would dissent from withdrawing 'regular' care. The initiation of medication with the intention of bringing about the death of a baby who becomes self-sustaining following disconnection from a ventilator or who is surviving with 'minimal' care, apart from being illegal, is even more ethically controversial and indeed, as appears in the Dutch report, would seem to be supported at present by only a minority of paediatricians there. Even they would intervene in this way only for babies whose life is predicted with 'all possible certainty' to be so filled with suffering that death is seen as a more humane alternative than life. In this circumstance most neonatologists in the UK would adopt the policy of allowing nature to take its course by avoiding additional interventions if they became indicated for the purpose of prolonging the life further (for example, the use of antibiotics in a life-threatening infection).

Even in Holland it has been claimed that most decisions concerning the end of life in children involve non-treatment decisions, not active euthanasia (4).

Adoption of the inactive approach, occupying a different moral standpoint, is perhaps not surprising and Chiswick (5), in his commentary on Doyal and Wilsher's guidelines (3) has touched on one possible reason that may underly the desire to avoid involvement with hastening the death of those not requiring intensive care. This derives from the experience that many paediatricians will have had in the process of co-operating with parents and other health care workers in setting up support services for families of very severely damaged children. Such support services aim to satisfy parental needs as well as the best interests of the child. However, although these services may impact upon the child's welfare, the paediatrician's compliance with parental wishes may not necessarily be always in the child's bes interests. Indeed, such children do survive and have rights but not necessarily, it may be claimed, for life $\vec{T}$. prolonging treatment so much as for ordinary loving care and comfort. Increasing support for such an approach, which excludes euthanasia, is probable or? humanitarian grounds as the needs of the handicapped are increasingly voiced.

Whilst the openness and increasing publi $\frac{\bar{c}}{\bar{c}}$. involvement in these issues that has occurred in recent years, and which is very apparent in the्e Dutch report, is to be welcomed, individual differences in moral outlook are likely, as in Holland ${ }_{2}^{\circ}$ to result in different approaches to the managemen $E_{0}$ of severely damaged infants by paediatricians in spite of coherent moral arguments put forward by ethicists, even when those arguments fall withir existing and sometimes tested national legat frameworks.

$R P A$ Rivers, MB, FRCP, is Reader in Paediatrics and an Honorary Consultant Paediatrician at St Mary's Hospital Medical School, London.

\section{References}

(1) Versluys Z, de Leeuw R. A Dutch report on the ethic $\vec{e}$ of neonatal care. Fournal of medical ethics 1995; 81 . 14-16.

(2) Sauer P J J. Ethical decisions in neonatal intensive units: the Dutch experience. Pediatrics 1992; 927-932.

(3) Doyal L, Wilsher D. Towards guidelines fo: withholding and withdrawal of life prolonging treatment in neonatal medicine. Archives of diseases $i \overrightarrow{\overline{\mathrm{b}}}$ childhood (Fetal and neonatal edition) 1994; 70马 F66-F70.

(4) Visser H K A. Personal communication. 1994.

(5) Chiswick M L. Commentary on reference (3): F70.
Submitting manuscripts for publication

Papers submitted for publication should be sent in quadruplicate to: The Editor, fournal of Medical Ethics, c/o Imperial College of Science, Technology and Medicine, 14 Prince's Gardens, London SW7 1NA. The journal considers papers only if they are not under consideration by any other journal at the same time. Rejected manuscripts are not returned. Papers should be in double-spaced typewriting on one side of the paper only. The preferred maximum length of papers is 3,500 words - absolute maximum $5,500 \quad$ (including references). A total word count (including references) is required. On a separate sheet some brief biographical details should be supplied, including the title of the author's present post, degrees and/or professional qualifications (if any), and any other relevant information.

Two copies of the journal will be sent to authors free of charge after their papers are published. Offprints of individual papers may be bought from fournal of Medical Ethics, BMA House, Tavistock Square, London WC1H 9JR.

In March 1981 the $\mathscr{F M E}$ adopted a simplified 'Vancouver style' for references: details are given in $\$$ various issues, including December $₹$ 1990. They are also available from the editorial office. The full text of the 'Vancouver Agreement' was published in the British Medical No fournal in 1988; volume 296;- 0 401-405. As the 'Vancouver style' $\$$ is incompatible with the long established style of references for legal articles, lawyers should used their own standard style, but try to facilitate reference by others. The? journal is multidisciplinary and $\phi$ papers should be in clear jargonfree English, accessible to any intelligent reader. 